\title{
State-by-State Look at Medicaid Retail Pharmacy Delivery: Trials \& Triumphs
}

\author{
As states shift the delivery of Medicaid benefits, including retail \\ pharmacy, to managed care Medicaid insurers, related cost-control \\ shifts are occurring around the country.
}

Mary Ellen McPeak

\section{Author}

MARY ELLEN MCPEAK is Senior Writer for Emron, Totowa, NJ.

Copyright $\odot$ 1998, Academy of Managed Care Pharmacy, Inc. All rights reserved.
$\mathrm{Y}$ ear after year, the number of Medicaid enrollees in managed care increases. Between 1992 and 1997, even with the total Medicaid population remaining fairly stable, the number of recipients served through managed Medicaid programs rose from 2.7 million to 13.3 million. Medicaid managed care enrollment increased fourfold, from $9.5 \%$ to $40 \%$ of eligible recipients. ${ }^{1}$

Medicaid managed care enrollment can be either voluntary or mandatory. The use of Section 1915b waivers (freedom of choice) and Section 1115 waivers (typically, pilot programs of predetermined duration to determine services or reimbursement requirements for expansion of a state's Medicaid benefits) increases access. As of March 1997, the Health Care Financing Administration (HCFA) had granted 114 waivers across the nation. ${ }^{2}$ Currently, only Alaska and Wyoming have yet to switch their Medicaid recipients into managed care. At the other end of the spectrum, 31 states have at least $50 \%$ of their Medicaid eligibles in a managed care plan, with Arizona and Tennessee providing managed care as their sole source of Medicaid benefits. Although some managed care plans, especially those new to the Medicaid market, have withdrawn from Arizona, California, Connecticut, New York, New Jersey, Pennsylvania, and other states, blaming inadequate reimbursement rates, national enrollment in Medicaid managed care programs continues to increase as states are asked to assume responsibility for greater numbers of needy patients.

Although the latest enrollment statistics are imposing, they probably represent only the tip of the managed care iceberg. Overall, within the next decade, an estimated $80 \%-90 \%$ of the American population will receive care through an integrated service network that provides primary, specialty, and hospital services. As a result, Medicaid enrollment rates in managed care are likely to continue to increase for at least three reasons:

A States now have the right to mandate Medicaid eligibles into managed care plans.

A More health maintenance organizations (HMOs) now can bid for Medicaid contracts because the $75 / 25$ law, which required that managed care plans enroll a minimum $25 \%$ of commercially insured enrollees along with its Medicaid enrollees, has been repealed.

A Some low-income populations now can buy into Medicaid plans, paying a sliding fee scale.

\section{THE MANAGED MEDICAID PHARMACY BENEFIT}

A pharmacy benefit is part of every state's traditional Medicaid program and, under law, managed care plans must provide equal coverage to the state's benefit program, even if it exceeds the coverage available to other plan members. For example, some state formularies cover selected over-the-counter drugs, typically nonsteroidal antiinflammatory drugs, cough and cold remedies, antihistamines, antacids, and vitamins. Furthermore, most states require no or very low copayments from Medicaid patients. State Medicaid formularies also 
rely heavily on generic equivalents, an aspect that commercial managed care plans weicome.

Currently, Medicaid fee-for-service (FFS) reimbursement rates to pharmacies are higher than those of third-party insurers.' According to a National Pharmaceutical Council survey, most state programs (55\%) calculate reimbursement rates using average wholesale price (AWP) minus $10 \%$ or $10.5 \%$ Alaska, California, Minnesota, Nebraska, Ohio, Virginia, and Wyoming have higher reimbursement rates, discounting AWP rates by less than 10\%. Connecticut, Delaware, Michigan, New Hampshire, New Mexico, Utah, and West Virginia have deeper discounts of $12 \%-$ $13 \%$, bringing them closer to the average for commercial third-party payors.

Average dispensing fees paid to retail pharmacies for Medicaid prescriptions also vary widely. In addition, many states have a range of dispensing fees, with 'differentials set according to specific criteria, such as outpatient dispensing versus long-term care dispensing, or brand versus generic dispensing. The average dispensing fee ranges from $\$ 3-\$ 4.50$ per prescription. Across the board, the cost of a prescription in the United States rose last year by $\$ 2.80$ to an average of $\$ 35.89$, according to data in the Novartis Pharmacy Benefit Report: 1998 Facts and Figures.

\section{STATE-LEVEL CHANGES IN PERCENT OF MEDICAID RETAIL PHARMACY DOLLARS}

Figure 1 shows the degree of change in FFS Medicaid dollars spent at the retail pharmacy level. Starting on the East Coast, Pennsylvania's share of FFS Medicaid pharmacy dollars fell $11.6 \%$, largely as a result of the state's first foray into managed Medicaid. ${ }^{3}$ Its new \$11 billion program, Health Choice, is only operational in the state's most populous area-the five-county Philadelphia region. Moving into the Midwest, data show that Michigan's level of Medicaid pharmacy reimbursement dipped only $1.3 \%$ after the introduction of managed Medicaid

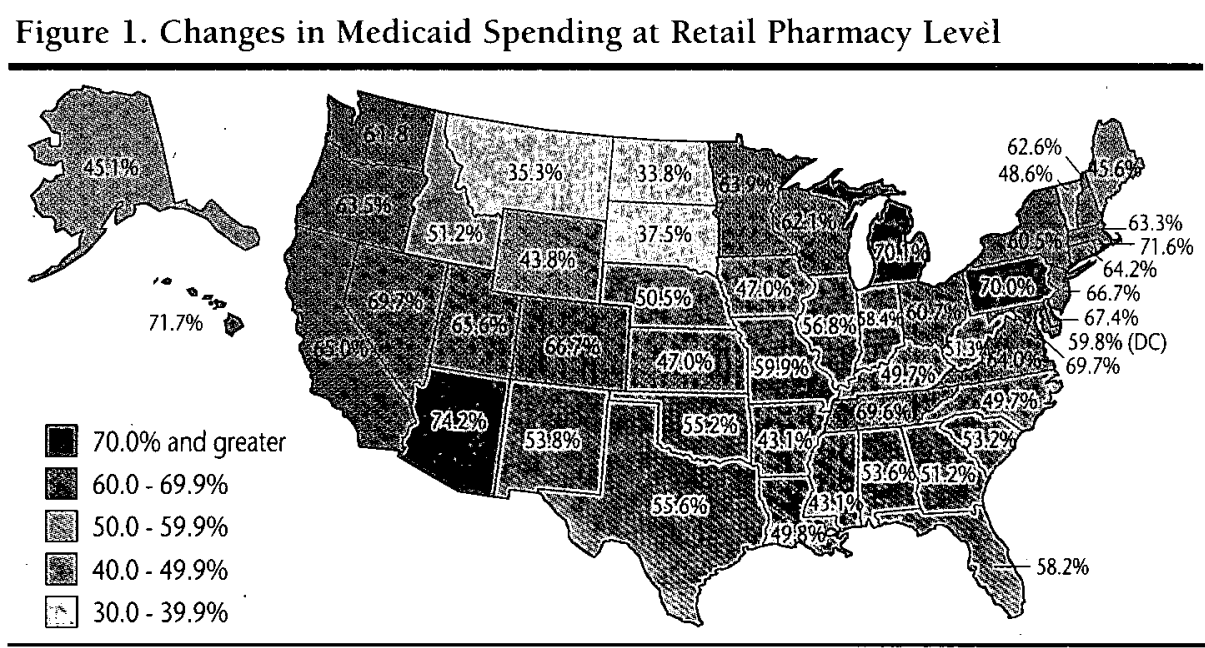

Source: Novartis Pharmacy Benefit Report: IMS Health Retail Method of Payment Report

into Detroit and surrounding counties. State-reimbursed pharmacy retail spending is expected to decrease again next year, however, because Michigan is pushing for its managed mental health plans to add a pharmacy benefit. In Utah, the rate of change in Medicaid dollars moved down 2.1\% -an impressive achievement, considering that Utah has carved in an FFS Medicaid pharmacy benefit plan. State administrators largely attribute this accomplishment to the state's computerized, centralized, real-time Medicaid drug utilization program, which contains the name of every Medicaid enrollee in its database.

States experiencing less control over their traditional Medicaid retail drug reimbursement levels include Kentucky, New York, and North Carolina. Kentucky has seen its FFS Medicaid pharmacy spending increase $39 \% .{ }^{3}$ There are at least two reasons for this predicament: 1) the state's goal is to introduce managed Medicaid into its counties on an incremental, region-by-region basis-a tactic Kentucky hopes will avoid some of the implementation/service delivery problems incurred by its neighbor, Tennessee, which switched all its traditional Medicaid enrollees into a managed care program in one fell swoop; and 2) there has been a lack of interest in accepting managed care Medicaid members from adequate potential insurers.
The job of cost-effectively administering New York's FFS Medicaid pharmacy benefit program has been daunting. Retail dollars reimbursed grew $21.2 \%$ from 1996 to 1997, $\$ 609$ million more than FFS Medicaid in California, the state with the second highest Medicaid pharmacy tab. ${ }^{3}$ In the past, New York carved in pharmacy benefit delivery for Medicaid enrollees diagnosed with HIV/AIDS. During the next few years, the state will be carving in all Medicaid pharmacy delivery. This tactic will, for the first time, allow the state to collect statewide Medicaid pharmacy utilization data via a systematic, linked process - a process that should eventually help New York better control its FFS Medicaid expenditures.

In a similar vein, North Carolina experienced an $11.3 \%$ increase in FFS Medicaid pharmacy dollars spent, ${ }^{3}$ and, at the same time, the state ranked first in growth $(25 \%)$ of third-party reimbursed retail prescriptions. North Carolina has been moving Medicaid eligibles in the Charlotte region into managed care Medicaid programs. In addition, it is in the process of developing a disease management program for Medicaidinsured children with asthma. Other programs have opened access to greater numbers of Medicaid eligibles, some served by commercial plans and some under state benefit management (retail reimbursement). 


\section{Continued from page 547}

Faced with increasing drug costs and increasing Medicaid enrollment, managed care pharmacists have their cost accountability work cut out for them. This Promethean task is likely to become more difficult, because most states initially targeted the healthiest members of their Medicaid population-young women and children-for enrollment. Now is the time to provide services for the other Medicaid enrollees-those patients who account for one-quarter of enrollees but two-thirds of health care expenditures.

\section{NATIONAL SHIFTS EXPANDING OPPORTUNITIES FOR PHARMACISTS AT STATE LEVEL}

Shifts in the way the Medicaid pharmacy benefit is reimbursed are influencing corresponding shifts throughout the health care industry. Both retail and hos pital-based pharmacists are affected. No longer viewed as merely product purveyors who simply deliver the salves, syrups, and syringes from behind a counter, pharmacists are being recognized as strategic players in the struggle to maximize pharmacologic benefits and minimize adverse events and ineffective health care expenditures. Pharmacists are earning the right to be financially reimbursed for educational services, as are other health care professionals, especially for services provided in clinical settings.

Emerging fields for pharmacists include:

A drug utilization review and drug use evaluation programs (DUR/DUE);

cognitive services; and

$\boldsymbol{\Delta}$ disease management programs (DMs).

\section{STRATEGIES FOR MANAGED MEDICAID ENROLLEE PHARMACY BENEFIT PROGRAMS}

\section{Data Management for DUR/DUE}

Initially, Medicaid administrators viewed DUR programs as a way to identify patients guilty of drug benefit fraud and drug abuse. Today, identifying physician and/or patient-oriented abuse while still important, is a secondary consideration among the many benefits achievable with effectively designed, online, real-time DUR/DUE data systems.

Utah's experience with DUR systems offers a prime example of the health care enhancements that other states can achieve for their Medicaid enrollees. In Utah, a state with a carved-in FFS pharmacy benefit and an open formulary, currently available drug review and evaluation options include programs that monitor a patient's file for duplicate therapies, drug-disease contraindications, drug-drug interactions, minimum/maximum dose levels for children and adults, and pregnancy-related contraindications. On average, the Medicaid data system processes about 160,000 prescriptions per month, flagging about 30,000 , or $19 \%$, for review. Of these, about 1,300 , or $4 \%$, of prescription claims are denied based on DUR warnings, according to Duane Parke, R.Ph., M.H.A., drug utilization review program manager, Utah Department of Health. Utah's Medicaid Prospective Drug Utilization Review Program saved the state an estimated $\$ 4$ million- $\$ 5$ million in avoided hospital admissions and physician office visits, according to Ray Dell Ashley, its Medicaid pharmacy/ health program director.

The state's pharmacists, by doing their DUR homework, enabled the Utah program to identify and prevent a number of narcotic/acetaminophen-combination adverse events, as well as to forecast and avert the phentermine/fenfluramine (phen/fen) disaster before it came onto. the national radar screen.

Another state making progress in the battle to redirect costs to risk insurers is New Jersey. Its Medicaid pharmacy spending dropped by $8.6 \%$, with overall third-party share of prescriptions increasing by $19.6 \%{ }^{3}$ The state has 10 managed care plans providing a pharmacy benefit, including the Mercy Health Plan of New Jersey, a plan managed by HMO Blue, the Medicaid arm of Blue Cross and Blue Shield of New Jersey.

Since the spring of 1997, Mercy has been reviewing the pharmacy data of its
100,000 members $-75 \%$ of whom are children, and $10 \%-15 \%$ of whom are asthmatics-for signs of therapy compliance. Scanning for signs of patient noncompliance, Leslie Lotano-Saba, R.Ph., M.S., director of pharmacy services, routinely checks for optimal asthma therapy compliance.

Patients identified as possibly noncompliant or not treated optimally, based on the National Institutes of Health guidelines, are considered candidates for an asthma intervention program when their data indicates they: 1 ) use acute care albuterol inhalers too often; 2) do not often receive long-term control therapies; and 3) only infrequently get breakthrough asthma-attack drugs. The care coordinator provides follow-up with these patients and is likely to refer them to the plan's asthma DM program.

Mercy has yet to determine savings accrued via fewer asthma-related emergency room and hospital admissions Studies demonstrate, however, that patients admitted for an acute exacerbation who go on to enroll in a DM program are three to four times less likely to be readmitted for asthma during the next three months.

\section{COGNITIVE SERVICES}

Because the pharmacy benefit remains a therapeutic linchpin of managed care plans, pharmacists are in an excellent position to demonstrate how their proactive services markedly enhance the value and reduce the risks associated with pharmaceutical care. The Omnibus Reconciliation Act of 1990 supports funding of demonstration projects to evaluate payment for cognitive services, and many cognitive services studies around the United States are demonstrating how pharmacist services add to overall positive health care outcomes, although few are reimbursed or recognized. Fiscal redress, however, may be on the horizon; the U.S. Congress has "expressed interest in reimbursing pharmacists" for reducing provider services that affect Medicaid or Medicare drug 
Table 1. Community Pharmacist-Provided Cognitive Services

\begin{tabular}{l|l|l|l}
\hline State of Service & Rendered & Outcome & Estimated Savings \\
\hline $\begin{array}{l}\text { Nebraska \& Iowa } \\
\text { Kansas }\end{array}$ & $\begin{array}{l}19 \text { pharmacies/ } \\
1 \text { month }\end{array}$ & $\begin{array}{l}\text { 25 pharmacies/ } \\
1 \text { month interventions }\end{array}$ & $\begin{array}{l}\text { \$1.178 million in avoided ER } \\
\text { \& physician office visits/month }\end{array}$ \\
\hline Texas & $\begin{array}{l}4 \text { pharmacies/ } \\
2 \text { months }\end{array}$ & 47 Rx interventions & $\begin{array}{l}\text { \$20,795 in avoided services } \\
\text { or } \$ 6.13 \text { returned to health } \\
\text { physician office visits/month }\end{array}$ \\
\hline Arkansas & $\begin{array}{l}\text { 30 pharmacies/ } \\
1 \text { month }\end{array}$ & $\begin{array}{l}\text { 421 Rx interventions } \$ 1 \text { spent on Rxs } \\
\text { for Medicaid } \\
\text { population }\end{array}$ & $\begin{array}{l}\$ 12,880 \text { in avoided ER \& } \\
\text { physician office visits }\end{array}$ \\
\hline
\end{tabular}

spending. Canada's subsidized healthcare program, for example, already reimburses pharmacists for saving the system money.

Under that insurance program, pharmacists in at least one province are reimbursed for cognitive services. They are paid $\$ 15$ to alter, terminate, or replace a medication in order to prevent a drug-related event, and $\$ 7$ not to dispense a drug they deem harmful under the circumstances. Additionally, and more to the point, a recent study demonstrated that pharmacists who are reimbursed for such interventions are more likely to intervene and document their activities.

Table l'identifies recent statewide studies ${ }^{4-7}$ that demonstrate the value of pharmacist intervention in overall health cost control. Interventions include prescribing errors, such as wrong drugs or doses, and drug-drug interactions.

\section{DISEASE MANAGEMENT OPPORTUNITIES}

In a benchmark decision by HCFA, Mississippi became the first state in the country to allow pharmacists to bill Medicaid directly for DM services rendered. Medicaid, however, will not reimburse state HMOs for this service. This inaugural development allows Medicaid to reimburse a "credentialed" retail pharmacist for a service beyond drug dispensing. Initial services covered will include four therapeutic areas: anticoagulation, asthma, diabetes, and hyperlipidemia This process is intended to help individuals identified by their physician as medication noncompliant. To educate Medicaid beneficiaries about their conditions and medications, the disease management program will require a pharmacist to spend 15-30 minutes privately with each patient. Each recipient will be limited to 12 consultations per year per condition, with a $\$ 20$ flat fee per appointment. Ultimately, the program's objective is to reduce the incidence of costly and avoidable hospital admissions and emergency room visits.

It is assumed that this DM breakthrough in Mississippi will spread to other states. With that in mind, the National Association of Boards of Pharmacy has called for an industry-wide coalition to establish a national credentialing system so that all interested pharmacists can provide DM programs across state lines.

Although there are numerous cases of nonphysician provider DM programs around the country, so far traditional Medicare is the only government-funded program that pays for nonphysician services under certain circumstances. Within the parameters of specific managed care programs, pharmacists participating in such services as anticoagulation clinics have been able to bill Medicare for services provided in those clinics, but the method of billing was indirect. For example, under an entirely legal pricing scheme known as the "incident to" rule, under specific circumstances, health care services provided by a nonphysician provider can be billed as if the physician performed them. In incidences like this, the amount billed is less than a physician would charge, and it is submitted to Medicare encoded at the nurse practitioner service rate, according to James Taylor, Pharm.D., of the Department of Pharmacy Practice at the University of Florida at Gainesville.

Pharmacist-managed anticoagulant clinics operate under a physician-approved protocol. A physician reviews each patient's chart and is available for consultations concerning patients whose warfarin (Coumadin) therapy is difficult to control. Numerous studies have demonstrated that these clinics can improve anticoagulation control, patient compliance, and clot-related complications.

According to the Agency for Health Care Policy and Research, appropriate use of oral anticoagulants could reduce strokes secondary to atrial fibrillation by $50 \%$ and save $\$ 600$ million annually. With the total cost of stroke estimated at $\$ 30$ billion per year in the United States, and the estimated mean lifetime cost of an ischemic stroke about $\$ 91,000$, systematic, pharmacist-managed anticoagulant programs are proving to be less costly and more effective than nonsystematic physician care procedures.

Table 2 demonstrates health care utilization/cost savings achieved through DM services. ${ }^{8.10}$

\section{CONCLUSION}

Only a few years ago, as Medicaid patients began to flood into managed care waiver programs, states held that drug prescription costs should be transferred to the commercial plan that accepted these patients. The pharmacy benefit was usually managed as a carveout by the plan (i.e., passed on to a pharmacy benefit manager). However, the cost of supplying the pharmacy benefit remained difficult to finance under the typical state formulary package. Today, states with managed Medicaid experience say that it is essential to maintain control of the pharmacy benefit 
Continued from page 552

Table 2. Pharmacist-Staffed Disease Management Programs

\begin{tabular}{l|l|l|l}
\hline State & Intervention & Population & Estimated Savings \\
\hline Arizona & $\begin{array}{l}\text { Anticoagulant } \\
\text { program }\end{array}$ & 660 patients & $\begin{array}{l}81 \% \text { reduction in hospitaliza- } \\
\text { tions and } \$ 154,350 \text { in costs }\end{array}$ \\
\hline Mid-Atlantic Region & $\begin{array}{l}\text { Anticoagulant } \\
\text { program }\end{array}$ & 104 patients & $\begin{array}{l}49 \% \text { reduction in ER/ } \\
\text { hospitalizations- } \$ 200,000 \\
\text { in costs per } 4.5 \text { months }\end{array}$ \\
\hline Maryland & $\begin{array}{l}\text { Diabetes } \\
\text { program }\end{array}$ & 437 patients & $\begin{array}{l}\$ 89,287 \text { comprehensive net } \\
\text { benefit per year }\end{array}$ \\
\hline
\end{tabular}

or, at the very least, develop a statewide, seamless link to all Medicaid providers and patients. These states have found that it takes an integrated, shared-risk system to deliver cost-effective, highquality patient outcomes across the entire continuum of health care. Obviously, pharmacists have a clear consulting and administrative role to play as such programs develop.

As long ago as 1975, Dr. John Millis reported in the Study Commission on Pharmacy, "Delivering pharmaceutical products to the patient is not, or should not be, an end in itself. Rather, drug preparation and distribution is but a means to an end, the end being the enhanced health and well-being of patients." Twenty years later, this observation has become a mandate to pharmacists. The opportunities attainable to pharmacists in the new Medicaid systems will be short-lived if drug utilization practices and medical benefits cannot be effectively managed. Pharmacists who seize the opportunity to incorporate their comprehensive skills into the evolving Medicaid care systems will be in the best position to thrive professionally, to establish adequate reimburseand to move pharmaceutical therapies into their appropriate place within treatment protocols. ment techniques for their contributions,

\section{$\Delta$} References

1. Novartis Pharmacy Benefit Report: 1998 trends $\&$ forecasts. Totowa, NJ: Emron, from the IMS . Health Retail Method of Payment Report 1998: 34 2. Fubini S, Limb S, Morgan SH. 1998 guide to managed care markets. Bethesda, MD: Health Trends, Inc., 1998: 55

3. Novartis Pharmacy Benefit Report: 1998 facts \& figures. Totowa, NJ: Emron; 1998: 9-11.

4. Fincham J, Hospodka R, Scoll D. The true value of pharmacist care. Nat Assoc Retail Druggists J 1995(March): 29-31

5. Fincham J, Hunter J. Documenting the worth of pharmacist care. Nat Assoc Retail Druggists J 1996(April): 29-32

6. Dobie RL, Rascati KL. Documenting the value of pharmacist intervention. Arizona Pharmacist 1994(Sep/Oct): 8-11.

7. McCormack J, Reinhardı G, Hastings J, McGuirt R. Documented value Arkansas study shows pharmacists who get paid document more interventions. Nat Assoc Retail Druggists J 1996(March): 39-41.

8. Grahl $C$. Why begin an anticoagulation clinic? Disease State Management, Managed Healthcare: www.modernmedicine.com/mhc/dsm2sbl.

9. Meszaros L. Getting a handle on efficacy and costs in anticoag therapy. Disease State

Management, Managed Healthcare: www.modernmedicine.com/mhc/dsm2.html.

10. Lai LL, Sorkin AL. Cost benefit analysis of pharmaceutical care in a Medicaid population (from a budgetary perspective). J Managed Care Pharm 1998; 4: 303-08. 